Jodoform, dessen safranähnlicher Geruch an die Stelle des früheren stechenden trat. Letztere mit Aetzkali in Berührung gebracht, erstarrte zu einer compacten Masse von Jodoform.

Schliesslich bemerke ich zur Erklärung:

Jod in Gegenwart von Salpetersäure, als oxydirende Substanz, zersetzt den Alkohol, bildet Jodal, Jodothyl, und salpetrigsaures Aethyloxyd. Ein Theil Jodal in Gegenwart von Salpetersäure bildet Dijodessigsäure, welche nicht flüchtig ist; zugleich destillirt ein Theil Jodal sammt den gebildeten ätherischen Verbindungen in Folge der durch die chemische Action hedingten Temperaturerhöhung über.

L. Berlandt, A potheker.

\title{
Ueber Mehluntersuchungen.
}

Von W. Danckwortt.

In Städten, die Schlacht- und Mahlsteuer haben, kommt es bekanntlich öfter vor, dass Roggenmehl mit Weizenmehl, welches eine viel höhere Steuer zahlt, gemischt und dann als Roggenmehl declarirt und bestenert wird. In streitigen Fällen soll dann der chemische Sachverständige darüber entscheiden. Dieser ist in um so grösserer Verlegenheit, als das einzige bis jetzt empfohlene Verfahren; das von $\mathrm{Bamihl}$ angegebene, von anderen und zwar bedeutenden Sachverständigen angegriffen wird.

Dies besteht bekanntlich darin, dass das fragliche Mehl mit reiner (ausgegohrener und völlig ausgewaschener) Kleie und Wasser zu einem Teig gebracht wird, dieser in zwei einander locker umschliessende Beutel aus.seidenem Müllertuch zwischen Nr. 10 und 14 gebracht und unter fortwährendem zufliessenden Wasser so lange ausgewaschen wird, als dies noch Stärkemehlkügelchen absondert. Aus der Beschaffenheit der zurückbleibenden Kleie, die dann ebenfalls zurúckbleibenden Kleber enthält, soll man auf dem Gehalt an Weizenmehl schliessen können. 
Viele Chemiker behaupten nun, dass die Mischung von Roggen - und Weizenmehl verändernd auf die mechanische Beschaffenheit des Klebers einwirke; dass die Verschiedenheit des Wassers Einfluss auf diesen ausübe, kurz — dass das Verfahren keine sichern Resultate erwarten lasse.

Dies war mir bekannt; es war mir aber auch bekannt, dass die wissenschaftliche Deputation des Ministerium der Medicinal-Angelegenheiten sich fü r Zulässigkeit dieses Verfahrens ausgesprochen hatte, und so entschloss ich mich, in einer Appelsache eine solche Untersuchung anzunehmen.

Da mir keine präcisen Vorversuche bekannt waren, musste ich zuerst Resultate danach zu gewinnen suchen. $\mathbf{Z u}$ dem Ende habe ich eine Anzahl Versuche mit reinem Roggenund reinem Weizenmehl, dann mit solchem mit Kleie gemischt, dann mit Mischungen beider Sorten Mehl in verschiedenen Verhältnissen vorgenommen, aber ich sagte mir gleich, dass ein einigermassen sicheres Resultat sich nur dann erwarten lasse, wenn die Versuche mit der Wage in der Hand vorgenommen würden. Demgemäss wurde dann auch verfahren; das Gewicht des inneren Beutels wurde genau bestimmt; das Mehl, die Kleie waren sorgfältig in Wasserbade ausgetrocknet, und es wurden alle Verluste sorgfaltig zu vermeiden gesucht; ausserdem wurde der Rückstand im Bentel nach dem Auswaschen zwei Tage lang im Wasserbade ausgetrocknet. - Die Versuche mit reinem Mehl verliess ich sehr bald, da der zurückbleibende Kleber äusserst schwierig auszutrocknen ist, während die Mischungen mit Kleie ein verhältnissmässig constantes Resultat gaben. Wenn ich sage verhältnissmässig, so wolle man bedenken, wie viele Umstände ein Schwanken desselben veranlassten. Vor Allem war es der dem innern Beutel äusserlich anhängende Kleber, dessen Entfernung sich durch Abwaschen nicht vollständig und gleichmässig bewerkstelligen liess; dazu kamen noch einige andere Verlustquellen, so dass das Verfahren kein absolut genaues Resultat erwarten liess. Dies war nun folgendes. $10 \mathrm{Grm}$. Roggenmehl mit $1 \mathrm{Grm}$. Weizenkleie gemischt gaben nach dem Auswaschen mit destillirtem Wasser, das bis zum Auf- 
hören des Milchigwerdens fortgesetzt war, in seidenem Beutelchen von Müllertuch Nr. 12 eingeschlossen, nach Abzug des Gewichts des Beutels und der Kleie

$$
\text { einen Rückstand v. 0,5-0,8\%; }
$$

rein. Weizenmehl, ebenso behandelt

do

v. $7,0-8,0 \%$;

Mischungen von 7,5 Grm. Roggenmehl mit

2,5 Grm. Weizenmehl einen Ruickstand von

Mischungen von 5,0 Grm. Roggenmehl mit

5,0 Grm. Weizenmehl einen Rückstand von $3,0-3,5 \%$.

Dies waren die Durchschnitte von je drei Proben der Mehlsorten, und je drei Proben der Misohungen.

Auf diese Versuche gestützt, habe ich geglaubt eine Untersuchung des fraglichen Mehls anstellen zu können, und das Resultat war, dass sämmtliche (sieben) Proben desselben einen Rückstand von 1,0-2,2 hinterliessen. Ich habe demnach nicht anders gekonnt, als dieselben als eine Mischung von Roggenmehl mit Weizenmehl zu erklären, und zwar habe ich geglaubt sie als eine Mischung von 70-75\% Roggenmehl mit $25-30 \%$ Weizenmehl angeben zu müssen.

Bamihl giebt an, dass die Beschaffenheit des Rückstandes im Beutel in Bezug auf Lockerung oder Zusammenhang auf den Kleber- (also ursprünglich Weizenmehl-) Gehalt schliessen lassen. Das ist richtig; auch bei meinen Proben zeigte reines Weizenmehl den Rückstand in einer fast in Eins zusammenhängenden Masse, während reines Roggenmehl ihn ganz locker erscheinen liess, Mischungen von beiden ihn in zusammengeklebten, etwa linsengrossen Stücken zeigten. Auch das fragliche Mehl zeigte dies Verhalten. Indessen möchte ich darum weniger Gewicht darauf legen, weil es nach dem Austrocknen gelingt durch Drücken und Reiben des Beutels den Inhalt desselben so zu zerkleinern, dass es nicht mehr möglich ist ihn von dem Rückstande reinen Roggenmehls zu unterscheiden. Auch die Loupe und das Mikroskop lassen dabei in Stich.

Natürlich habe ich nicht unterlassen bei dieser Untersurchung auch noch andere Unterscheidungsmerkmale aufzusuchen. Na-

Arch. d. Pharm. OXCV. Bds. 1. Hft. 
mentlich habe ich auch auf das mikrosk. Verhalten des Roggen - $n$. Weizenmehls Rücksicht genommen. Indessen ist dies doch sehr misslich. Man sieht ja auf einzelnen Körnern des Roggenstärkemehls die Längs - und kreuzförmigen Spalten, aber nicht auf allen, und ich würde es desshalb doch für sehr misslich halten, darauf einen Unterschied des Roggen- und Weizenmehls aussprechen zu wollen. Nur Eins ist mir aufgefallen, und darauf möchte ich die Aufmerksamkeit der Sachverständigen lenken. Mir ist es so vorgekommen, als ob, - sobald man Roggen - und Weizenmehl unter dem Mikroskop der Einwirkung sehr verdünnter Jodtinctur aussetzt - die Stärkekügelchen des Weizenmehls schneller und intensiver blau gefärbt würden, als die des Roggenmehls. Es kann ja sein, dass das auf subjectiver Täuschung beruht, oder dass andere Ursachen (wie Feinheit des Mehls) darauf eingewirkt haben; jedenfalls möchte ich mir darüber das Urtheil Kenntnissreicherer erbitten. 